Remarks. - That the fatal termination of this case was not a thing to be surprised at will be the opinion of most readers, as well as that Cæsarean section would not have been more successful. My opinion is that the unavoidable hxmorrhage, and the shock of eutting through the abdominal wall, laying bare the abdominal cavity, and dividing the uterine wall, would have caused the diseased and debilitated patient to die on the table. Had she been less violent, or strong enough to have justified one in giving morphia, or continuing the anæsthesia, her life might probably have been prolonged. That laparo-ely trotomy is a simple and feasible operation, I believe every reader will admit. It avoids almost all the capital dangers of Cæsarean section, and is not more difficult. The wound is much less extensive, the peritoneam and uterus are not wounded at all, nor the abdominal cavity exposed to danger from infective fluids, cold, or mechanical injury; the danger of hæmorrhage is much less, the shock is less, and the delivery of the child is quite as easy. As compared with craniotomy, this operation is simplicity itself, and the results hitherto obtained much better, being absolutely good for the child instead of absolutely fatal, and for the mother most salutary results have also ensued. Had the cancerous growth in this case been less extensive, so as to leave, say, a passage of three inches in the vagina, and had craniotomy been tried, would any better result have been probable for the mother after the deliberate destruction of the child? I scarcely think so. Craniotomy, when practised with perfectly healthy tissues, is most unsatisfactory in its results for the mother, and I cannot but think that in such a case as this the unavoidable laceration of the diseased tissues which must have ensued, with consequent hæmorrhage, the tediousness of the operation, and the shock incident on it, must have led to a fatal termination in so enfeebled a patient. Even supposing the peritoneal cavity should be accidentally opened, the wound will be far less than in Cæesarean section, and the wound will be situated so as to favour, as far as possible, the escape of any blood, \&c., from the abdominal cavity. Considering the easy nature of the operation, the certainty of saving the child, and the strong probability (judging from Dr. Thomas's report) of saving the mother, it is a question how far craniotomy will ever again be justifiable, and whether Cxsarean section should not drop into oblivion. I found my opinion more on the experience of Dr. Thomas and Dr. Skene, than on my own single case. But the demonstration in this case of the truth and probability of what had been accomplished by the distinguished New York surgeons makes me think that the introduction (or revival) of this operation will exercise a great influence on operative midwifery in the future. The child is at present thriving. Sheffield.

\section{NOTES OF THREE SUCCESSFUL CASES OF HERNIOTOMY.}

BY GEORGE ELDER, M.B.,

SURGEON TO THE HOSPITAL FOR WOMEN, NOTTINGHAM.

CASE 1. Strangulated femoral hernia; operation; recovery.-On Oct. 10th, 1876, I saw Mrs. D-, aged fiftyfive, shopkeeper, in consultation. She gave the history of an old-standing femoral hernia, for which she had worn a truss. Some twenty-four hours before I saw her she had been called to a customer in the shop, and neglected to put on her truss. In lifting a heavy weight she suddenly felt pain at seat of rupture, and was obliged to take to bed. Sickness and abdominal pain soon supervened, and an attempt at taxis was made by Dr. Davison, of Carlton, but unsuccessfully. When I was called in patient was lying on her back, with legs drawn up, incessantly vomiting. Below Poupart's ligament on the left side there was a moderatesized, tense, and tender tumour, which gave no impulse on coughing. Patient's general condition was fairly good. Chloriform having been administered, I gently attempted reduction by the taxis, and this failing a vertical incision was made through the skin and superficial fascia. By means of the finger Gimbernat's ligament was felt and incised by a probe-pointed bistoury, and the tumour, with its sac intact, returned into abdominal cavity. The wound having been sponged out with carbolised water ( 1 in 20$)$, the edges were brought together with silk. A compress, a few strips of plaster, and a spica bandage, completed the operation. For four days subsequently sufficient opium was given to quiet the bowels, and the diet was restricted to iced milk and soda-water. On that day the dressing was taken off, and on withdrawal of sutures, union by first intention having taken place, only a few strips of plaster to support the newly-formed tissue, and piece of dry lint, were applied. The bowels were moved on the eighth day by means of castor oil, and on the ninth, with a well-fitting truss, she was allowed to get up and go about.

CASE 2. Strangulated umbilical hernia; operation; recovery.-Mrs. H-, aged sixty-two, was admitted into the Women's Hospital on Dec. 19th, 1876. Patient was very fat, and for years had suffered from an irreducible hernia. Twenty hours before admission, in attempting to lift the kettle off the fire, she felt "something give way," and was faint and sick. She at once took to bed, and had warm applications to pained part. On the morrow she was seen by a medical man, who advised removal to hospital. On admission she was found to have a very large umbilical hernia, the skin over which was excoriated in places and attenuated, and pressure on tumour caused pain. The folds of intestine could be felt through thinned integument. Constipation, stercoraceous vomiting, and frequently recurring and severe abdominal pains, were present. The general condition of the patient was not hopeful. She was exceedingly depressed and exhausted. My friend, Dr. Morris, gave ether, and, failing to relieve patient by the taxis, I made a pretty long longitudinal incision through the skin. Feeling with my finger around the ring of integument surrounding the neck of the tumour, I found the constricting part at its lower margin. Into this I made a pretty free incision with a probe-pointed bistoury, after which a part of the contents of the tumour fell back into the abdomen. Believing I had done all that was necessary to relieve the strangulation, and not desirous of putting my patient to the very grave danger of opening the sac and exploring its contents, I brought together the edges of the wound, and finished the operation in the usual way. Although this patient had an intercurrent and pretty severe attack of acute bronchitis, she made a very good, though rather tedious, recovery.

CASE 3. Femoral hernia in a man; strangulation; operation; recovery. — "George $\mathrm{R}-$, aged sixty-two, labourer, living at Arnold, was first seen by Dr. Reid on May 14th, 1877. He then complained of intense pain in the left iliac region, frequent vomiting, and constipation. Three days previously, whilst lifting a ladder with another man, the latter let go his hold, and patient received a blow on the left side. Giving himself a twist in trying to keep his balance, something gave a 'crack,' and immediately he felt a pain at the site of rupture. He also states that some years before he had a rupture on the same side. On examination, a tense, elongated swelling, irregular in outline, and about the size of a man's fist, was found in the left iliac region and passing down over Poupart's ligament. By the taxis an inguinal hernia evidently was reduced, but there remained still a tumour extending in a line parallel to the inguinal canal for about two inches and a half from and above Poupart's ligament. It was rather of a conical shape, with base inferiorly. Percussion note was dull over it, but gurgling could be heard on pressure at the apex of the tumour, which was tense and hard. The taxis failed to reduce it, and the patient declined further operative interference. However, on the following morning he consented. He now suffered great pain, had frequent stercoraceous vomiting, and was in a state of great exhaustion." At this juncture I was telegraphed for, and concurring with Dr. Reid as to the nature of the case, patient was put under the influence of chloroform. A vertical incision was made over the tumour through skin and superficial fascia, and Gimbernat's ligament incised. This failing to reduce the tumour, an opening was made into the sac, and rather firm adhesions having been broken down by the finger between the bowel and sac, its neck was freely divided. The bowel was deeply purplish, but in no place did it show any signs of gangrene. At the period of incision of the sac-neck there was rather profuse bleeding at the bottom of the wound. This ceased spontaneously shortly after the return of the bowel to the abdominal cavity. The edges of the wound were brought together by silver wire, and a firm compress and bandage were applied. "For two days the patient did well, but on the third he became feverish, had occasional vomiting and general abdominal pain. There was con. 
siderable tenderness over the abdomen, and at the seat of rupture there was a distinct and tender swelling. Fearing bleeding had taken place, Dr. Reid withdrew the sutures, and removed from the cavity of the wound several clots. A small vessel at the bottom of the wound, evidently the cause of the mischief, was with difficulty twisted. The wound was then washed out with carbolised oil ( 1 in 20), and allowed to granulate. Fourteen days after the operation, a large slough, probably a portion of the sac, came away in the discharge. In six weeks from the date of operation the patient was well." The above notes in inverted commas were kindly sent me by Dr. Reid, to whose skilful treatment much of the success was due.

Nottingham.

\section{FATAL CASE OF INTESTINAL CATARRH IN A CHILD.}

BY CHAS. E. BARNARD, M.D., GOVERNMENT MEDICAL OFFICER.

As death from intestinal catarrh in young children is not very common, I should imagine, I forward, for insertion in THE LANCET, the particulars of the post-mortem examination of a child who had died after only two days' illness with this complaint.

Catherine $\mathrm{N}$ - aged two years and nine months, was seized on the evening of the 23rd August with vomiting and purging, and complained of pain in the stomach. The child had taken nothing apparently to account for the symptoms. In addition to the food vomited, a watery fluid came up. The stools at first were natural, but afterwards became white or milky-looking. The child was very restless, pale, and cold. Its eyes became sunken, its hands clenched, and every now and then it drew its arms up as if in pain. These are the symptoms I was told it suffered from preceding its death. It died on the afternoon of the 25th. The only medicine the child had was a dose of castor oil on the 24th, and some chlorodyne (four minims in all) from a chemist who prescribed this. The child, though, had this medicine only about three or four hours before its death.

As the coroner decided to have an inquest, I made the post-mortem examination. The body was well nourished. The upper lobes of each lung were pink-coloured and perfectly natural. The lower lobe of each was dark-coloured and deeply congested. The right side of the heart contained dark clots and dark fluid blood, while the left side contained decolorised fibrine with only a slight quantity of fluid blood. This clot seemed to run up into the aorta and block up the passages. The stomach, jejunum, and upper portion of ileum were filled with a brown, thick, ropy fluid; more fluid in the stomach than in the intestines. Where intestines were filled with this mucous secretion, the walls were thickened or swollen and of a purplish colour, the vessels being deeply injected. I could find no sign of ulceration in them. The rest of the small intestines presented a great contrast, as they were perfectly natural in colour and texture, and contained only a slight amount of mucus. Could detect no food in the bowel. The large intestine also was natural, but contained a milky-looking fluid, small in quantity, which lined the mucous membrane. The line of demarcation between the inflamed portion of the small intestine and the rest which was healthy, was well marked; as the bowel was not only of a purplish colour, but distended more or less with the thick mucous secretion, while the healthy bowel was paler in colour and somewhat flattened from absence of any contents. At first I imagined there was an obstruction at the spot where the distension ended. This was negatived on further examination. Neither was there any intussusception, which I carefully looked for. Altogether, the amount of inflammation of the bowels, it seemed to me, was too slight to cause such severe constitutional disturbance as to lead to death.

The immediate cause of the fatal termination was, of course, the formation of the large clots in the heart; but why these should form so quickly puzzled me, unless the congestion of the lungs had something to do with it. The child was running about the day preceding its death, and the mother said no appearance of danger was noted till the morning of the day of its death.
The treatment adopted-chlorodyne-had probably some. thing to do with the fatal termination; but of this I cannot be certain, as the child was evidently in a very low state before this medicine was given. A purgative, accompanied with ammonia and alkalies, would be more indicated, in my opinion, than opiates. Milk and lime-water would also have been invaluable.

Gulgong, N.S.w.

\section{dy attlitror}

\section{HOSPITAL PRACTICE,}

\section{BRITISH AND FOREIGN.}

Nulla autem est alia pro certo noscendi via, nisi quamplurimas et morborm et dissectionum historias, tum aliorum, tum proprias collectas habere, et inter se comparare.--Morga gri De Sed. et Caus. Morb., lib. iv. Procmium.

\section{METROPOLTTAN FREE HOSPITAL.}

CASE OF UNUSUALLY HIGH THERMOMETRIC REGISTRATION

(Under the care of Dr. ORMERoD.)

For the notes of the following remarkable case, in which the temperature rose to $115^{\circ} 8^{\circ}$, we are indebted to Mr.W.S. Bryne, M.B., senior house-surgeon.

Ann $\mathrm{C}-$, aged thirty-two years, married, and the mother of four children, a pale, weakly-looking woman, nervous and hysterical, was admitted on the night of August 23rd, 1878. It appeared from her history that she had enjoyed very good health up to four months before, when she suffered from an attack of acute rheumatism, for which she was treated in this hospital, having been confined to bed for four weeks. She discharged herself before she was well, with a temperature of $104^{\circ}$. She had never since ceased to suffer from pains in the joints, back, and abdomen, where the pain was most intense, especially in the right hypochon. driac region.

When admitted, her face was pale, with a cold clammy perspiration on the forehead; she had a haggard, anxious expression, and complained of intense pain in her side. She was hardly able to walk; and her pulse was feeble and 120. She was immediately put to bed, and hot jars were placed at her feet. Nothing abnormal could be discovered either in the chest or abdomen, nor any symptoms of cardiac disorder or spinal disease; and the joints were neither red nor swollen.

She slept fairly during the night, and expressed herself as better in the morning, except as respects the pain in the right hypochondrium, which she compared to scalding water, and which she begged to have taken away from her. When the abdomen was pressed up and down, a kind of slushing sonnd was distinctly heard, which very much resembled that emitted from a churn; but the abdomen was free from any enlargement, and the percussion sounds were normal. Urine was free from albumen. A small blister was applied over the right hypochondrium the morning after her admission, she was placed on low diet and given bark and ammonia. For the next three or four dar: the temperature remained at from $100^{\circ}$ to $101^{\circ}$, and then sank to normal, when it was not considered necessary t register it any longer. She still complained much of the pain in the side. Half-grain doses of morphia were given hypodermically every night, but the patient objected to them, as she said they made her head bad. About this time she had a fainting fit, supposed to be hysterical from the many little symptoms of hysteria she showed. She seemed to improve in her general health, though nothing seemed to relieve her side. Poultices and hot fomentation: were useless, and iodide of potash and bark, hyoscranin and valerian, bromide of potassium, and bicarbonate of potast and hyoscyamus were given in vain.

On the 11th of September she seemed flushed and excite: the head was hot, with great throbbing of the tempor: arteries; the pulse went up to 140 per minute, and the thermometer registered $107^{\circ}$. Some mistake as regards th latter having been suspected, it was again taken, and regis tered $105^{\circ}$. The thermometer was placed in the asilla of a 